\title{
Circadian rhythm and atherosclerosis (Review)
}

\author{
ZAIQIANG ZHANG ${ }^{1,2^{*}}$, BIN YU $^{1,2^{*}}$, XINAN WANG $^{1,2}$, CAIYUN LUO $^{1,2}$, \\ TIAN ZHOU ${ }^{1,2}$, XIAXIA ZHENG ${ }^{1,2}$ and JIAWANG DING ${ }^{1,2}$ \\ ${ }^{1}$ Department of Cardiology, The First College of Clinical Medical Sciences; \\ ${ }^{2}$ Institute of Cardiovascular Diseases, China Three Gorges University, Yichang, Hubei 443000, P.R. China
}

Received April 5, 2020; Accepted August 11, 2020

DOI: $10.3892 / \mathrm{etm} .2020 .9224$

\begin{abstract}
Atherosclerosis is the leading cause of morbidity and mortality worldwide. The underlying pathogenesis involves multiple metabolic disorders, endothelial dysfunction and a maladaptive immune response, and leads to chronic arterial wall inflammation. Numerous normal physiological activities exhibit daily rhythmicity, including energy metabolism, vascular function and inflammatory immunoreactions, and disrupted or misaligned circadian rhythms may promote the progression of atherosclerosis. However, the association between the circadian rhythm and atherosclerosis remains to be fully elucidated. In the present review, the effects of the circadian rhythm on atherosclerosis progression are discussed.
\end{abstract}

\section{Contents}

1. Introduction

2. Biological characteristics of the circadian rhythm

3. Circadian rhythm and atherosclerosis

4. Circadian rhythm and glycolipid metabolism

5. Circadian rhythm and vascular cells

6. Circadian rhythm and inflammatory immunoreactions

7. Conclusions

\section{Introduction}

Atherosclerosis is an inflammatory disease and previous studies have demonstrated that the underlying pathology of atherosclerosis is mainly the damage to vessel walls caused by lipid metabolism disorders and the inflammatory immune

Correspondence to: Dr Jiawang Ding, Department of Cardiology, The First College of Clinical Medical Sciences, China Three Gorges University, 183 Yiling Road, Yichang, Hubei 443000, P.R. China E-mail: dingjiawang@163.com

*Contributed equally

Key words: circadian rhythm, endothelial cells, macrophages, vascular smooth muscle cells response, leading to abnormal lipid deposition in the intima and its underlying smooth muscle, plaque formation and vascular stenosis (1). Unstable atherosclerotic plaques are likely to rupture and cause thromboembolism, which may result in serious clinical events including acute coronary syndrome and myocardial infarction. Atherosclerosis is a chronic inflammatory condition in which a variety of cell types and physical and chemical factors are involved (2). A mounting body of evidence suggests that these cytokines involved in atherosclerosis exhibit circadian oscillations (3).

\section{Biological characteristics of the circadian rhythm}

All organisms on Earth, from bacteria to plants and mammals, have intrinsic body clocks that respond to environmental changes by controlling the major physiological activities. In mammals, the central pacemaker of the circadian rhythm exists in the suprachiasmatic nucleus (SCN) of the hypothalamus and consists of 24-h oscillations present in most cells of the body (4). These oscillations are of particular relevance to physiological and biochemical functions, including sleep/wake cycles, feeding behavior and activity rhythms (4). The core of the molecular clock is the transcription factor heterodimer circadian locomotor output cycle kaput (Clock)/brain and muscle aryl hydrocarbon receptor nuclear translocator-like protein 1 (Bmal1), which is driven by two key negative feedback loops that generate 24-h oscillations of daily activity (5), as presented in Fig. 1. The first important feedback loop consists of Clock, Bmall, period circadian clock (Per) and Cryptochromecircadian clock (Cry). In this loop, Clock/Bmall binds to E-box DNA elements to upregulate Per and Cry levels (3). Per and Cry then accumulate in the cytoplasm and form a complex with the serine-threonine kinase casein kinase $1 \varepsilon / \delta(\mathrm{CK} 1 \varepsilon / \delta)$, which translocates to the nucleus to repress its own transcription and Clock/Bmall activity, thereby forming a negative

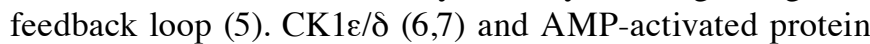
kinase (AMPK) (8) phosphorylate unbound Per and Cry, respectively, to promote their degradation. Numerous studies have also demonstrated that other kinase networks, including glycogen synthase kinase-3, PI3K/Akt and MAPKs, are able to phosphorylate Per and Cry to promote their degradation (9). The second feedback loop consists of Clock, Bmall, nuclear receptor subfamily 1 , group D, member 1 (REV-ERB) $\alpha$ and $-\beta$, and orphan nuclear receptor (ROR) $\alpha,-\beta$ or $-\gamma$. Clock/Bmall activate the negative regulators $\mathrm{REV}-\mathrm{ERB} \alpha$ and $-\beta$ and the 
positive regulators ROR $\alpha,-\beta$ or $-\gamma(10,11)$. REV-ERBs bind to the retinoic acid-related orphan receptor response element located in the Bmal1 promoter to inhibit transcription (12). An increasing number of studies have indicated that the molecular clock has an important role in almost all metabolic processes in organisms. Furthermore, disruptions to the circadian rhythm may lead to cardiovascular diseases (13), type 2 diabetes (14) and immune system diseases (15).

\section{Circadian rhythm and atherosclerosis}

The progression of atherosclerosis is characterized by the accumulation of fatty deposits in the inner layer of arteries. It is well known that the development of atherosclerosis is related to lipid metabolism, inflammatory reactions, endothelial cell dysfunction and immune function, and there is growing evidence that circadian rhythms have a critical role in the development and progression of the condition. For instance, it was reported that low density lipoprotein receptor $(\mathrm{Ldlr})^{-/-}$and apolipoprotein E (Apoe) ${ }^{-/ /}$mice with global Clock knockout fed a standard chow diet developed more lesions at the aortic arches and aortic root (16), and that upregulated Cryl expression (17) or REV-ERB $\beta$ agonist delivery (18) reduced atherogenesis in $\mathrm{Ldlr}^{-/}$and $\mathrm{Apoe}^{-/}$mice.

\section{Circadian rhythm and glycolipid metabolism}

Circadian rhythm and glycometabolism. Glycometabolism is a complex physiological process. In humans, the daily variation in insulin secretion and insulin sensitivity over $24 \mathrm{~h}$ displays an obvious diurnal rhythm (19). Buxton et al (20) demonstrated that the risk of insulin resistance/type 2 diabetes may be reduced if shift workers focus on improving sleep duration and implementing circadian readjustment strategies (such as sleeping during the biological night and eating during the biological day). Glucose tolerance is higher in the morning than in the evening and at night (21). Impaired glucose tolerance of type 2 diabetes (22) appears when the circadian oscillation of the glycometabolism is disrupted. The neural and peripheral clocks regulate the enzymes of glycolysis, fatty acid oxidation and oxidative phosphorylation during the 24-h day to guarantee that these enzymes function at the appropriate times during the process of glycometabolism (23-25), which is associated with the circadian rhythm at the transcriptional level.

A large number of animal experiments and clinical studies have reported that glucose tolerance and diabetes are closely related to circadian rhythm disorders. In a laboratory test, rodents with SCN lesions exhibited whole or partial clock gene disruptions and developed glycometabolic disorders, including impaired glucose tolerance (26), $\beta$-cell failure (27), decreased insulin sensitivity (28), hyperglycemia (29) and hyperinsulinemia (29). Clock- (29) or Bmal1- (30) mutant mice exhibit impaired glucose tolerance, reduced insulin secretion and decreased pancreatic islet proliferation. Furthermore, a study involving mice with Clock gene mutations reported dampening of the oscillations of hepatic glycogen and glycogen synthase 2 and expression of the limiting enzyme of glycogenesis (31). Pancreas- or $\beta$-cell-specific Bmal1-knockout mice had elevated plasma glucose levels, impaired glucose tolerance and decreased insulin secretion. In addition, repression of Per2 expression resulted in reduced plasma glucose levels, enhanced insulin secretion and impaired gluconeogenesis (32). However, in mice lacking Cry1 and Cry2, plasma glucose levels were elevated in response to acute feeding after a 12-h overnight fast (33). REV-ERB $\alpha$ is able to regulate plasma glucose homeostasis by controlling the expression of glucose-6-phosphatase and phosphoenolpyruvate carboxylase. REV-ERB $\alpha$-mutant mice on a high-fat diet had increased adiposity and mild hyperglycemia without insulin resistance (34). In general, these studies demonstrate that the circadian clock system possibly maintains the homeostasis of glycometabolism by regulating the activities of the key enzymes of glycometabolism (35).

Circadian rhythm and lipid metabolism. Levels of serum lipids also display an obvious circadian rhythm. For instance, plasma levels of lipids exhibit day-night variations independent of food intake, suggesting that the circadian clock is an important regulator of lipid metabolism (36). However, the peak level of plasma high-density lipoprotein (HDL) appears in the early rest phase and decreases during the active phase (37). A prospective clinical study suggested that an unhealthy lifestyle and poor-quality sleep predict the development of hyperlipidemia and obesity with age (38). Another study suggested that reduced sleep duration in children contributes to an increased risk of being overweight (39). It is therefore indicated that circadian rhythm disorders are associated with lipid metabolism in mammals. In a clinical study on a population with obesity, the expression of REV-ERB $\alpha$ exhibited a marked positive correlation with the body mass index and waist circumference, and the expression of ROR $\alpha$ and Clock was correlated with HDL and low-density lipoprotein (LDL) levels, respectively (40). That study also indicated that the clock genes Cry 2 and REV-ERB $\alpha$ were upregulated in obesity over a 24-h period (40).

Animal experiments also indicated that clock gene mutations are closely associated with dyslipidemia. Pan et al (41) reported that compared to Apoe ${ }^{-/}$mice, Bmall ${ }^{-/}$Apoe $^{-/}$and Bmall in liver $(\mathrm{L}-\mathrm{Bmal1})^{-/} \mathrm{Apoe}^{-/-}$mice had an increased risk of hyperlipidemia and atherosclerosis but that L-Bmal1 ${ }^{-/-}$Apoe $^{-/}$mice with adenovirus-mediated liver overexpression of Bmal1 had a reduced risk of hyperlipidemia and atherosclerosis. A recent study suggested that Bmall functions as a positive regulator of vascular smooth muscle cell (VSMC) proliferation following vascular injury (42), and liver-specific Bmall- or REV-ERB $\alpha$-knockout mice exhibited increased levels of cholesterol, triglycerides and free fatty acids (43). Furthermore, physiological studies have demonstrated that enterocytes expressing the dominant-negative Clock mutant protein $\left(\right.$ Clock $^{\Delta 19 / \Delta 19}$ ) protein absorb more cholesterol from the intestinal lumen and secrete cholesterol and chylomicrons (16). This evidence indicates that Clock has a vital role in the regulation of cholesterol metabolism. Additional supporting evidence for circadian clock involvement has revealed that other core clock genes are associated with lipid metabolism. Grimaldi et al (44) indicated that Per2 was a natural modulator controlling the proadipogenic activity of peroxisome proliferating activated receptor (PPAR) $\gamma$ and a major regulator of lipid metabolism. In addition, Per1/2-null mice or Per2-null mice had lower hepatic triglyceride levels than wild-type mice (37). Furthermore, REV-ERB $\alpha$ deficiency may cause marked hepatic steatosis (10), and mice lacking REV-ERB $\alpha$ displayed reduced levels of hepatic triglycerides and cholesterol and elevated levels of plasma lipids (45). 


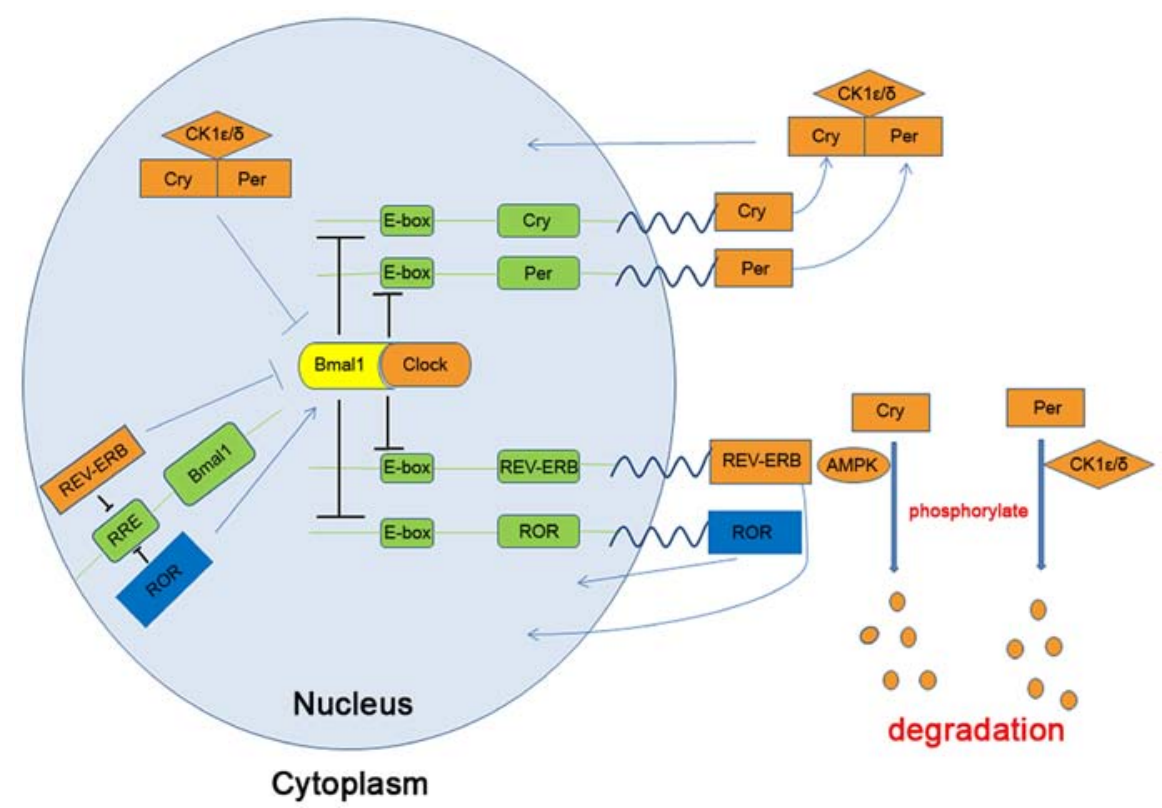

Figure 1. Schematic of the molecular clock consisting of two key negative feedback loops. Bmall, brain and muscle aryl hydrocarbon receptor nuclear translocator-like protein 1; Clock, circadian locomotor output cycles kaput; Cry, Cryptochromecircadian clock; Per; Period circadian clock; REV-ERB, nuclear

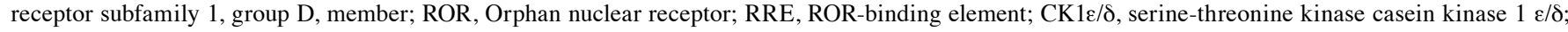
AMPK, AMP-activated protein kinase.

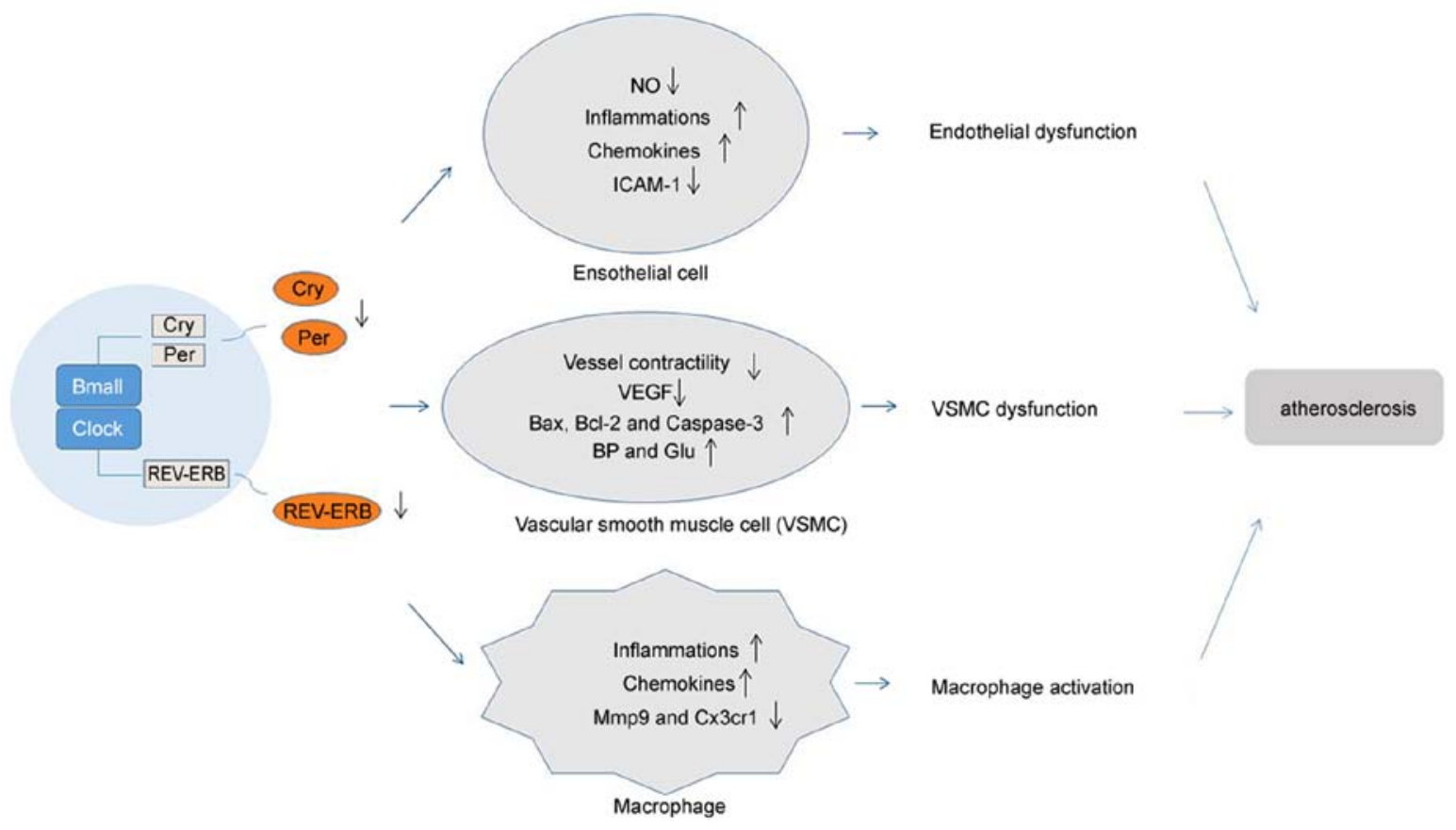

Figure 2. Schematic: The circadian clocks exerts effects on endothelial cells, vascular smooth muscle cells and macrophages and may have potential roles in atherosclerosis. Bmal1, brain and muscle aryl hydrocarbon receptor nuclear translocator-like protein 1; Clock, circadian locomotor output cycles kaput; Cry, Cryptochromecircadian clock; Per; Period circadian clock; REV-ERB, nuclear receptor subfamily 1, group D, member; NO, nitric oxide; ICAM-1, intercellular adhesionmolecule-1; VEGF, Vascular endothelial growth factor; Bcl-2, B-cell lymphoma 2; Bax, Bcl-2-associated X protein; BP, blood pressure; Glu, glucose; Mmp9, matrix metalloproteinase9; Cx3cr1, CX3C chemokine ligand receptor 1.

\section{Circadian rhythm and vascular cells}

Emerging evidence indicates that circadian rhythm have a very close connection with vascular cells with regard to vascular function and health (46). Circadian rhythms influence the activities of systemic atherosclerosis mediators, including leukocytes and macrophages, and locally manipulate cells within the vessel wall. Indeed, studies have indicated that the functional circadian clock exists within the vasculature (47). A growing number of studies (48-55) have identified that circadian clocks regulate the functions of endothelial cells, VSMCs and macrophages, suggesting the possibility of circadian clocks to influence the progression of atherosclerosis (as presented in Fig. 2). In the present review, a series of clock 
Table I. Critical roles of circadian rhythm-associated genes in various types of vascular cell according to previous studies.

A, Endothelial cells

\begin{tabular}{lll}
\hline Gene & \multicolumn{1}{c}{ Function and result } \\
\hline Clock & $\begin{array}{l}\text { Loss of protective endothelial expression contributes to the vulnerability } \\
\text { of human carotid plaque. } \\
\text { Major role in the regulation of intravascular coagulation. }\end{array}$ \\
Bmal1 & $\begin{array}{l}\text { Increased production of nitric oxide and vasodilatory prostaglandin(s) and } \\
\text { decreased release of cyclooxygenase-1-derived vasoconstrictor(s). }\end{array}$ \\
\hline
\end{tabular}

B, Macrophages

Clock gene

Clock

Bmal1

REV-ERB $\alpha$
Function and result

(Refs) altered NF-KB-induced macrophage activation.

Regulates oxidative stress pathways in macrophages to limit the production of the proinflammatory cytokine IL- $1 \beta$.

Activation of REV-ERB $\alpha$ reduces the severity of inflammation in peritoneal

C, VSMCs

Clock gene

Function and result

(Refs)

Bmal1

Knockdown of Bmal1 promotes VSMC apoptosis by regulating Bax, Bcl-2, cytochrome c and caspase-3 levels.

Clock Knockdown of Clock promotes VSMC apoptosis by regulating Bax, Bcl-2, cytochrome c and caspase-3 levels.

REV-ERB $\alpha$

REV-ERB $\alpha$ upregulates NF-кB-responsive genes in VSMCs.

VSMC, vascular smooth muscle cell; Clock, circadian locomotor output cycle kaput; Bmal1, brain and muscle aryl hydrocarbon receptor nuclear translocator-like protein 1; Per; Period circadian clock; REV-ERB, nuclear receptor subfamily 1, group D, member; Bcl-2, B-cell lymphoma 2; Bax, Bcl-2-associated X protein.

genes with roles in vascular cells are presented. Those genes and their functions in different vascular cell types are listed in Table I.

Circadian rhythm and endothelial cells. It is generally known that dysfunction in the vascular endothelium is a pivotal factor in atherogenesis. Endothelial cells may be injured and accordingly activated by numerous stimuli, including oxidized LDLs, hypertension, hyperglycemia, turbulent blood flow and inflammation. Furthermore, endothelial cell activation leads to expression of adhesion molecules, loss of barrier function, migration of leukocytes into the vascular wall and improvement in inflammatory responses (46). Tang et al (48) indicated that loss of protective endothelial Clock expression contributes to the progression of atherosclerosis and aggravates plaque vulnerability. It appears that the circadian clock is able to regulate the release of nitric oxide (NO) and disruption of the clock leads to endothelial dysfunction (56). Endothelial dysfunction is associated with decreased bioavailability of endothelial NO, which is produced by endothelial NO synthase
(eNOS) and the relevant regulatory mechanisms of eNOS activity are closely interrelated with endothelial dysfunction in atherosclerosis (57). Human endothelial function is measured by flow-mediated dilation (FMD) and a recent study suggested that FMD was decreased in patients with congestive heart failure and that the circadian variation in endothelial function was deficient (58).

There is much evidence to support that Bmal1-knockout and Clock-mutant mice have endothelial dysfunction. Genetic ablation of the Bmal1 gene in endothelial cells enhances the expression of the chemokines $\mathrm{C}-\mathrm{C}$ motif ligand $(\mathrm{Ccl}) 8$, $\mathrm{Ccl} 20$ and chemokine (C-X-C motif) ligand $(\mathrm{Cxcl}) 5$, damages endothelial integrity and barrier function (59) and leads to phenotypic features similar to those of diabetes (60). Furthermore, Gao et al (61) reported that the circadian clock may drive endothelial cells to express intercellular adhesion molecule-1 and promote the adhesion of monocytes to endothelial cells. Viswambharan et al (50) indicated that mutation in the Per2 gene in mice is associated with aortic endothelial dysfunction involving decreased production of NO and 
vasodilatory prostaglandin and increased release of cyclooxygenase-1-derived vasoconstrictor. Carvas et al (62) concluded that Per2 gene mutation in aorta reduces insulin-stimulated NO release from endothelial cells. In a mouse model of sleep deprivation, Qin and Deng (63) indicated that sleep deprivation promoted the expression of proinflammatory cytokines and decrease that of Cry1 in vascular endothelial cells. Furthermore, Savalli et al (64) studied a naturalistic animal model of depression, concluding that chronic mild stress-induced anhedonic behavior is associated with disturbed diurnal oscillation of Clock, Cry 2 and Rev-ERB $\alpha$ expression in the mouse basolateral amygdala and that Clock gene desynchronization appeared to be involved in vascular endothelial growth factor (VEGF) variations. In general, it is well accepted that the circadian clock is important for maintaining normal endothelial cell functions.

Circadian rhythm and VSMCs. VSMCs constitute the vascular media. During atherosclerosis progression, the migration of VSMCs from the middle layer to the intima is of great significance (65). VSMCs are stimulated by a variety of cytokines and inflammatory cytokines; the phenotype of SMCs switches from contractile SMCs to secretory SMCs and VSMCs simultaneously proliferate and migrate to the intima. Specifically, VSMCs and the extracellular matrix are the major components of the neointima and subsequent vascular stenosis (66-68).

Studies have indicated that specific clock gene knockout of Bmall in VSMCs impairs vessel contractility and decreases the blood pressure; in addition, smooth muscle-specific Bmall has a vital role in normal VSM contraction (69). According to Suyama et al (70), Bmall knockdown resulted in a decrease in VEGF and VEGF receptor mRNA expression compared with the control. Furthermore, VSMCs cultured from the carotid arteries of healthy donors exhibited regular circadian mRNA expression of Bmal1, Per1, Per2, Per3, Cry1, Cry2 and Rev-ERB $\alpha$ (71). In addition, the circadian rhythm of the major rhythm genes isolated from human plaque-derived VSMCs is significantly attenuated compared to that from cells cultured from the carotid arteries of healthy donors (71). Similarly, hyperglycemia and hyperlipidemia are associated with circadian gene expression in VSMCs (72,73). Su et al (72) suggested that expression of Per1/2, Cry1/2, D site albumin promoter-binding protein (Dbp) and PPAR $\gamma$ in the aorta and mesenteric arteries in $\mathrm{db} / \mathrm{db}$ mice was suppressed compared with that in control mice. Specifically, Migita et al (55) reported that Rev-ERB $\alpha$ causes upregulation of NF-KB-responsive genes in VSMCs. These observations indicate that the circadian clock is of great significance to VSMC functions.

Circadian rhythmandmacrophages. Macrophages are involved in the formation of atherosclerosis and have a different role in atherosclerotic lesion development (46). Macrophage accumulation within the vascular wall is a hallmark of atherosclerosis. In atherosclerotic lesions, macrophages respond to various environmental stimuli, such as modified lipids, cytokines, and senescent erythrocytes, which can modify their functional phenotypes.Furthermore, an increase in the inflammatory reaction decreases plaque stability and results in a thrombotic event. Of note, as with VSMCs and endothelial cells, circadian rhythms are able to regulate macrophage function (74).
In the wall of vessels affected by atherosclerosis, macrophages secrete inflammatory factors, including chemokines and cytokines. Specifically, the cytokine storms of infected mice display the greatest reaction at the beginning of infection (75). In addition, circadian expression of monocyte chemoattractant protein-1 (MCP-1/JE) in macrophages is regulated by Bmall via activation of NF-kB (76). The molecular mechanisms by which cytokine production by macrophages is regulated remain to be fully elucidated. However, evidence indicates that the expression of Bmall is regulated by a circadian rhythm in macrophages (76). Rev-ERB $\alpha$ - or Bmal1-knockout macrophages displayed increased production of cytokines and decreased expression of circadian rhythm genes (75). Huo et al (77) concluded that Bmall deficiency in macrophages may exacerbate atherosclerosis by promoting the recruitment of Ly6Chi monocytes to atherosclerotic lesions. Similarly, compared to wildtype control mice, Clock-mutant mice have increased circulating IL-12 and IL-17 levels and altered NF-кB-induced macrophage activation $(16,51)$. Furthermore, Rev-ERB $\alpha$ regulate enhancer-derived RNAs, suppressing the expression of nearby genes, including Mmp9 and $\mathrm{CX} 3 \mathrm{C}$ chemokine ligand receptor $1(\mathrm{Cx} 3 \mathrm{crl}$; one of the most expressed genes in microglia in mice and humans, is implicated in numerous microglial functions) in macrophages (78), and Rev-ERB $\alpha$ modulate the inflammatory infiltration of macrophages by inhibiting the expression of Ccl2 (79). It remains elusive whether clock genes control local macrophage proliferation.

\section{Circadian rhythm and inflammatory immunoreactions}

The levels of immune inflammatory immunoreactive cells and pro-inflammatory cytokines have an obvious daily rhythm (80) and functionality of the immune system has been linked to the circadian clock (81). A recent study reported that circadian disruption by sleep fragmentation accelerates atherosclerosis development by increasing the number of circulating monocytes (82). Consequently, disturbed circadian clock function may contribute to the risk of atherosclerosis through the pro-inflammatory state. Based on in vivo and in vitro experiments, the circadian rhythm is closely linked to inflammatory immunoreactions $(52,83)$. In cells lacking Bmal1, lower expression of BMAL1 may affect mediators of inflammation and oxidative stress (52). Keller et al (74) indicated that Bmal1 mRNA expression in macrophages was lowest at the active phase (zeitgeber time 12). Furthermore, in animal models of inflammatory bowel disease (51), the expression of inflammatory factors in Clock gene-mutant mice was decreased compared with that in wild-type mice. In addition, the circadian rhythm expression of IFN- $\gamma$ disappeared in Per2-mutant mice (84). In an arthritis model (85), simultaneous knockout of Cry-1 and Cry-2 led to an increase in TNF- $\alpha$ and aggravated the inflammatory response. In addition, the clock genes Rev-ERB $\alpha$ and ROR $\alpha$ have important roles in inflammatory immunoreactions $(86,87)$.

\section{Conclusions}

Numerous studies have suggested that the circadian rhythm is significant regarding several aspects of atherosclerosis, 
including glycometabolism, lipid metabolism, endothelial cell dysfunction, VSMC phenotype and inflammatory immunoreactions. However, the mechanism of specific clock genes involved in the atherosclerotic process remains elusive. Thus, further research on the relationship between the circadian rhythm and atherosclerosis is required. There is much to learn about the circadian rhythm, promoting a healthy lifestyle that includes sufficient, regular sleep, this may provide novel therapeutic targets and preventative measures to simultaneously slow the development of atherosclerosis and reduce cardiovascular mortality.

\section{Acknowledgements}

Not applicable.

\section{Funding}

The present work was supported by the National Natural Science Foundation of China (grant nos. 81770456 and 81400794).

\section{Availability of data and materials}

Not applicable.

\section{Authors' contributions}

$\mathrm{ZZ}, \mathrm{JD}$ and $\mathrm{XW}$ conceived and designed the article. $\mathrm{ZZ}, \mathrm{BY}$, $\mathrm{CL}, \mathrm{XZ}$ and $\mathrm{TZ}$ collected related articles and analyzed the relevant literature. $\mathrm{ZZ}$ and $\mathrm{BY}$ wrote the manuscript and drew the figures. JD, CL, XZ, TZ and XW revised the manuscript. All authors read and approved the final version of the manuscript.

\section{Ethics approval and consent to participate}

Not applicable.

\section{Patient consent for publication}

Not applicable.

\section{Competing interests}

The authors declare that they have no competing interests.

\section{References}

1. Shah MS and Brownlee M: Molecular and cellular mechanisms of cardiovascular disorders in diabetes. Circ Res 118: 1808-1829, 2016.

2. Nguyen KD, Fentress SJ, Qiu Y, Yun K, Cox JS and Chawla A: Circadian gene Bmall regulates diurnal oscillations of Ly6C(hi) inflammatory monocytes. Science 341: 1483-1488, 2013.

3. Scheiermann C, Kunisaki Y and Frenette PS: Circadian control of the immune system. Nat Rev Immunol 13: 190-198, 2013.

4. Steffens S, Winter C, Schloss MJ, Hidalgo A, Weber C and Soehnlein O: Circadian control of inflammatory processes in atherosclerosis and its complications. Arterioscler Thromb Vasc Biol 37: 1022-1028, 2017.

5. Mohawk JA, Green CB and Takahashi JS: Central and peripheral circadian clocks in mammals. Annu Rev Neurosci 35: 445-462, 2012.
6. Lowrey PL, Shimomura K, Antoch MP, Yamazaki S, Zemenides PD, Ralph MR, Menaker M and Takahashi JS: Positional syntenic cloning and functional characterization of the mammalian circadian mutation tau. Science 288: 483-492, 2000.

7. Shirogane T, Jin J, Ang XL and Harper JW: SCFbeta-TRCP controls clock-dependent transcription via casein kinase 1-dependent degradation of the mammalian period-1 (Per1) protein. J Biol Chem 280: 26863-26872, 2005.

8. Lamia KA, Sachdeva UM, DiTacchio L, Williams EC, Alvarez JG, Egan DF, Vasquez DS, Juguilon H, Panda S, Shaw RJ, et al: AMPK regulates the circadian clock by cryptochrome phosphorylation and degradation. Science 326: 437-440, 2009.

9. Buhr ED and Takahashi JS: Molecular components of the Mammalian circadian clock. Handb Exp Pharmacol 217: 3-27, 2013.

10. Bugge A, Feng D, Everett LJ, Briggs ER, Mullican SE, Wang F, Jager J and Lazar MA: Rev-erb $\alpha$ and Rev-erb $\beta$ coordinately protect the circadian clock and normal metabolic function. Genes Dev 26: 657-667, 2012.

11. Solt LA, Wang Y, Banerjee S, Hughes T, Kojetin DJ, Lundasen T, Shin Y, Liu J, Cameron MD, Noel R, et al: Regulation of circadian behaviour and metabolism by synthetic REV-ERB agonists. Nature 485: 62-68, 2012.

12. Crumbley $\mathrm{C}$ and Burris TP: Direct regulation of CLOCK expression by REV-ERB. PLoS One 6: e17290, 2011.

13. Skogstad M, Mamen A, Lunde LK, Ulvestad B, Matre D, Aass H, $\emptyset v s t e b \varnothing$ R, Nielsen P, Samuelsen KN, Skare $\varnothing$ and Sirnes PA: Shift work including night work and long working hours in industrial plants increases the risk of atherosclerosis. Int J Environ Res Public Health 16: 521, 2019.

14. Laermans J and Depoortere I: Chronobesity: Role of the circadian system in the obesity epidemic. Obes Rev 17: 108-125, 2016.

15. O'Keeffe SM, Beynon AL, Davies JS, Moynagh PN and Coogan AN: NF- $\kappa B$ signalling is involved in immune-modulation, but not basal functioning, of the mouse suprachiasmatic circadian clock. Eur J Neurosci 45: 1111-1123, 2017.

16. Pan X, Jiang XC and Hussain MM: Impaired cholesterol metabolism and enhanced atherosclerosis in clock mutant mice. Circulation 128: 1758-1769, 2013

17. Yang L, Chu Y, Wang L, Wang Y, Zhao X, He W, Zhang $\mathrm{P}$, Yang X, Liu X, Tian L, et al: Overexpression of CRY1 protects against the development of atherosclerosis via the TLR/NF- $\kappa B$ pathway. Int Immunopharmacol 28: 525-530, 2015.

18. Sitaula S, Billon C, Kamenecka TM, Solt LA and Burris TP: Suppression of atherosclerosis by synthetic REV-ERB agonist. Biochem Biophys Res Commun 460: 566-571, 2015.

19. Kalsbeek A, la Fleur S and Fliers E: Circadian control of glucose metabolism. Mol Metab 3: 372-383, 2014.

20. Buxton OM, Cain SW, O'Connor SP, Porter JH, Duffy JF, Wang W, Czeisler CA and Shea SA: Adverse metabolic consequences in humans of prolonged sleep restriction combined with circadian disruption. Sci Transl Med 4: 129ra43, 2012.

21. Morris CJ, Yang JN, Garcia JI, Myers S, Bozzi I, Wang W, Buxton OM, Shea SA and Scheer FA: Endogenous circadian system and circadian misalignment impact glucose tolerance via separate mechanisms in humans. Proc Natl Acad Sci USA 112: E2225-E2234, 2015.

22. Polonsky KS, Given BD, Hirsch LJ, Tillil H, Shapiro ET, Beebe C, Frank BH, Galloway JA and Van Cauter E: Abnormal patterns of insulin secretion in non-insulin-dependent diabetes mellitus. N Engl J Med 318: 1231-1239, 1988.

23. Panda S, Antoch MP, Miller BH, Su AI, Schook AB, Straume M, Schultz PG, Kay SA, Takahashi JS and Hogenesch JB: Coordinated transcription of key pathways in the mouse by the circadian clock. Cell 109: 307-320, 2002.

24. Yang X, Downes M, Yu RT, Bookout AL, He W, Straume M, Mangelsdorf DJ and Evans RM: Nuclear receptor expression links the circadian clock to metabolism. Cell 126: 801-810, 2006.

25. McCarthy JJ, Andrews JL, McDearmon EL, Campbell KS, Barber BK, Miller BH, Walker JR, Hogenesch JB, Takahashi JS and Esser KA: Identification of the circadian transcriptome in adult mouse skeletal muscle. Physiol Genomics 31: 86-95, 2007.

26. Shi SQ, Ansari TS, McGuinness OP, Wasserman DH and Johnson CH: Circadian disruption leads to insulin resistance and obesity. Curr Biol 23: 372-381, 2013. 
27. Lee J, Moulik M, Fang Z, Saha P, Zou F, Xu Y, Nelson DL, Ma K, Moore DD and Yechoor VK: Bmall and $\beta$-cell clock are required for adaptation to circadian disruption, and their loss of function leads to oxidative stress-induced $\beta$-cell failure in mice. Mol Cell Biol 33: 2327-2338, 2013

28. Coomans CP, van den Berg SA, Lucassen EA, Houben T, Pronk AC, van der Spek RD, Kalsbeek A, Biermasz NR, Willems van Dijk K, Romijn JA and Meijer JH: The suprachiasmatic nucleus controls circadian energy metabolism and hepatic insulin sensitivity. Diabetes 62: 1102-1108, 2013

29. Turek FW, Joshu C, Kohsaka A, Lin E, Ivanova G, McDearmon E, Laposky A, Losee-Olson S, Easton A, Jensen DR, et al: Obesity and metabolic syndrome in circadian Clock mutant mice. Science 308: 1043-1045, 2005.

30. Rudic RD, McNamara P, Curtis AM, Boston RC, Panda S, Hogenesch JB and Fitzgerald GA: BMAL1 and CLOCK, two essential components of the circadian clock, are involved in glucose homeostasis. PLoS Biol 2: e377, 2004.

31. Doi R, Oishi K and Ishida N: CLOCK regulates circadian rhythms of hepatic glycogen synthesis through transcriptional activation of Gys2. J Biol Chem 285: 22114-22121, 2010.

32. Zani F, Breasson L, Becattini B, Vukolic A, Montani JP, Albrecht U, Provenzani A, Ripperger JA and Solinas G: PER2 promotes glucose storage to liver glycogen during feeding and acute fasting by inducing Gys2 PTG and G L expression. Mol Metab 2: 292-305, 2013.

33. Lamia KA, Papp SJ, Yu RT, Barish GD, Uhlenhaut NH, Jonker JW, Downes M and Evans RM: Cryptochromes mediate rhythmic repression of the glucocorticoid receptor. Nature 480 : 552-556, 2011.

34. Delezie J, Dumont S, Dardente H, Oudart H, Gréchez-Cassiau A Klosen P, Teboul M, Delaunay F, Pévet P and Challet E: The nuclear receptor REV-ERB $\alpha$ is required for the daily balance of carbohydrate and lipid metabolism. FASEB J 26: 3321-3335, 2012.

35. Tao H, Li X, Qiu JF, Cui WZ, Sima YH and Xu SQ: Inhibition of expression of the circadian clock gene Period causes metabolic abnormalities including repression of glycometabolism in Bombyx mori cells. Sci Rep 7: 46258, 2017.

36. Chua EC, Shui G, Lee IT, Lau P, Tan LC, Yeo SC, Lam BD, Bulchand S, Summers SA, Puvanendran K, et al: Extensive diversity in circadian regulation of plasma lipids and evidence for different circadian metabolic phenotypes in humans. Proc Natl Acad Sci USA 110: 14468-14473, 2013.

37. Adamovich Y, Rousso-Noori L, Zwighaft Z, Neufeld-Cohen A, Golik M, Kraut-Cohen J, Wang M, Han X and Asher G: Circadian clocks and feeding time regulate the oscillations and levels of hepatic triglycerides. Cell Metab 19: 319-330, 2014.

38. Spiegel K, Tasali E, Leproult R and Van Cauter E: Effects of poor and short sleep on glucose metabolism and obesity risk. Nat Rev Endocrinol 5: 253-261, 2009.

39. Lumeng JC, Somashekar D, Appugliese D, Kaciroti N, Corwyn RF and Bradley RH: Shorter sleep duration is associated with increased risk for being overweight at ages 9 to 12 years. Pediatrics 120: 1020-1029, 2007.

40. Vieira E, Eg R, Figueroa AL, Aranda G, Momblan D, Carmona F, Gomis R, Vidal J and Hanzu FA: Altered clock gene expression in obese visceral adipose tissue is associated with metabolic syndrome. PLoS One 9: e111678, 2014.

41. Pan X, Bradfield CA and Hussain MM: Global and hepatocyte-specific ablation of Bmall induces hyperlipidaemia and enhances atherosclerosis. Nat Commun 7: 13011, 2016.

42. Takaguri A, Sasano J, Akihiro O and Satoh K: The role of circadian clock gene BMAL1 in vascular proliferation. Eur J Pharmacol 872: 172924, 2020

43. Jacobi D, Liu S, Burkewitz K, Kory N, Knudsen NH, Alexander RK, Unluturk U, Li X, Kong X, Hyde AL, et al Hepatic Bmall regulates rhythmic mitochondrial dynamics and promotes metabolic Fitness. Cell Metab 22: 709-720, 2015.

44. Grimaldi B, Bellet MM, Katada S, Astarita G, Hirayama J, Amin RH, Granneman JG, Piomelli D, Leff T and Sassone-Corsi P: PER2 controls lipid metabolism by direct regulation of PPAR $\gamma$. Cell Metab 12: 509-520, 2010.

45. Le Martelot G, Claudel T, Gatfield D, Schaad O, Kornmann B, Lo Sasso G, Moschetta A and Schibler U: REV-ERBalpha participates in circadian SREBP signaling and bile acid homeostasis. PLoS Biol 7: e1000181, 2009.

46. McAlpine CS and Swirski FK: Circadian influence on metabolism and inflammation in atherosclerosis. Circ Res 119: 131-141, 2016.
47. Davidson AJ, London B, Block GD and Menaker M: Cardiovascular tissues contain independent circadian clocks. Clin Exp Hypertens 27: 307-311, 2005.

48. Tang H, Zhu M, Zhao G, Fu W, Shi Z, Ding Y, Tang X and Guo D: Loss of CLOCK under high glucose upregulates ROCK1-mediated endothelial to mesenchymal transition and aggravates plaque vulnerability. Atherosclerosis 275: 58-67, 2018.

49. Takeda N, Maemura K, Horie S, Oishi K, Imai Y, Harada T, Saito T, Shiga T, Amiya E, Manabe I, et al: Thrombomodulin is a clock-controlled gene in vascular endothelial cells. J Biol Chem 282: 32561-32567, 2007.

50. Viswambharan H, Carvas JM, Antic V, Marecic A, Jud C, Zaugg CE, Ming XF, Montani JP, Albrecht U and Yang Z: Mutation of the circadian clock gene Per2 alters vascular endothelial function. Circulation 115: 2188-2195, 2007.

51. Bellet MM, Deriu E, Liu JZ, Grimaldi B, Blaschitz C, Zeller M, Edwards RA, Sahar S, Dandekar S, Baldi P, et al: Circadian clock regulates the host response to Salmonella. Proc Natl Acad Sci USA 110: 9897-9902, 2013.

52. Early JO, Menon D, Wyse CA, Cervantes-Silva MP, Zaslona Z, Carroll RG, Palsson-McDermott EM, Angiari S, Ryan DG, Corcoran SE, et al: Circadian clock protein BMAL1 regulates IL-1 $\beta$ in macrophages via NRF2. Proc Natl Acad Sci USA 115: E8460-E8468, 2018

53. Pourcet B, Zecchin M, Ferri L, Beauchamp J, Sitaula S, Billon C, Delhaye S, Vanhoutte J, Mayeuf-Louchart A, Thorel Q, et al: Nuclear receptor subfamily 1 Group D Member 1 regulates circadian activity of NLRP3 inflammasome to reduce the severity of fulminant hepatitis in mice. Gastroenterology 154: 1449-1464. e20, 2018.

54. Chen L, Wu X, Zeb F, Huang Y, An J, Jiang P, Chen A, Xu C and Feng Q: Acrolein-induced apoptosis of smooth muscle cells through NEAT1-Bmal1/Clock pathway and a protection from asparagus extract. Environ Pollut 258: 113735, 2020.

55. Migita H, Morser J and Kawai K: Rev-Erbalpha upregulates NF-kappaB-responsive genes in vascular smooth muscle cells. FEBS Lett 561: 69-74, 2004.

56. Rodrigo GC and Herbert KE: Regulation of vascular function and blood pressure by circadian variation in redox signalling. Free Radic Biol Med 119: 115-120, 2018.

57. Yang $Z$ and Ming XF: Recent advances in understanding endothelial dysfunction in atherosclerosis. Clin Med Res 4: 53-65, 2006.

58. Maruo T, Nakatani S, Kanzaki H, Kakuchi H, Yamagishi M, Kitakaze M, Ohe T and Miyatake K: Circadian variation of endothelial function in idiopathic dilated cardiomyopathy. Am J Cardiol 97: 699-702, 2006.

59. Gibbs J, Ince L, Matthews L, Mei J, Bell T, Yang N, Saer B, Begley N, Poolman T, Pariollaud M, et al: An epithelial circadian clock controls pulmonary inflammation and glucocorticoid action. Nat Med 20: 919-926, 2014.

60. Bhatwadekar AD, Beli E, Diao Y, Chen J, Luo Q, Alex A, Caballero S, Dominguez JM, Salazar TE, Busik JV, et al: Conditional deletion of Bmall accentuates microvascular and macrovascular injury. Am J Pathol 187: 1426-1435, 2017.

61. Gao Y, Meng D, Sun N, Zhu Z, Zhao R, Lu C, Chen S, Hua L and Qian R: Clock upregulates intercellular adhesion molecule-1 expression and promotes mononuclear cells adhesion to endothelial cells. Biochem Biophys Res Commun 443: 586-591, 2014.

62. Carvas JM, Vukolic A, Yepuri G, Xiong Y, Popp K, Schmutz I, Chappuis S, Albrecht U, Ming XF, Montani JP and Yang Z: Period2 gene mutant mice show compromised insulin-mediated endothelial nitric oxide release and altered glucose homeostasis. Front Physiol 3: 337, 2012.

63. Qin B and Deng Y: Overexpression of circadian clock protein cryptochrome (CRY) 1 alleviates sleep deprivation-induced vascular inflammation in a mouse model. Immunol Lett 163: 76-83, 2015.

64. Savalli G, Diao W, Schulz S, Todtova K and Pollak DD: Diurnal oscillation of amygdala clock gene expression and loss of synchrony in a mouse model of depression. Int J Neuropsychopharmacol 18: pyu095, 2014.

65. Lacolley P, Regnault V, Segers P and Laurent S: Vascular smooth muscle cells and arterial stiffening: Relevance in development, aging, and disease. Physiol Rev 97: 1555-1617, 2017.

66. Feil S, Hofmann F and Feil R: SM22alpha modulates vascular smooth muscle cell phenotype during atherogenesis. Circ Res 94: $863-865,2004$ 
67. Rudolph V and Freeman BA: Cardiovascular consequences when nitric oxide and lipid signaling converge. Circ Res 105: 511-522, 2009.

68. Wang L, Zheng J, Bai X, Liu B, Liu CJ, Xu Q, Zhu Y, Wang N, Kong W and Wang X: ADAMTS-7 mediates vascular smooth muscle cell migration and neointima formation in balloon-injured rat arteries. Circ Res 104: 688-698, 2009.

69. Xie Z, Su W, Liu S, Zhao G, Esser K, Schroder EA, Lefta M, Stauss HM, Guo Z and Gong MC: Smooth-muscle BMAL1 participates in blood pressure circadian rhythm regulation. J Clin Invest 125: 324-336, 2015.

70. Suyama K, Silagi ES, Choi H, Sakabe K, Mochida J, Shapiro IM and Risbud MV: Circadian factors BMAL1 and ROR $\alpha$ control HIF-1 $\alpha$ transcriptional activity in nucleus pulposus cells: Implications in maintenance of intervertebral disc health. Oncotarget 7: 23056-23071, 2016.

71. Lin C, Tang X, Zhu Z, Liao X, Zhao R, Fu W, Chen B, Jiang J, Qian R and Guo D: The rhythmic expression of clock genes attenuated in human plaque-derived vascular smooth muscle cells. Lipids Health Dis 13: 14, 2014.

72. Su W, Xie Z, Guo Z, Duncan MJ, Lutshumba J and Gong MC: Altered clock gene expression and vascular smooth muscle diurnal contractile variations in type 2 diabetic $\mathrm{db} / \mathrm{db}$ mice. Am J Physiol Heart Circ Physiol 302: H621-H633, 2012.

73. Chen S, Ding Y, Zhang Z, Wang H and Liu C: Hyperlipidaemia impairs the circadian clock and physiological homeostasis of vascular smooth muscle cells via the suppression of Smarcd1. J Pathol 233: 159-169, 2014.

74. Keller M, Mazuch J, Abraham U, Eom GD, Herzog ED, Volk HD, Kramer A and Maier B: A circadian clock in macrophages controls inflammatory immune responses. Proc Natl Acad Sci USA 106: 21407-21412, 2009.

75. Gibbs JE, Blaikley J, Beesley S, Matthews L, Simpson KD, Boyce SH, Farrow SN, Else KJ, Singh D, Ray DW, et al: The nuclear receptor REV-ERB $\alpha$ mediates circadian regulation of innate immunity through selective regulation of inflammatory cytokines. Proc Natl Acad Sci USA 109: 582-587, 2012.

76. Hayashi M, Shimba S and Tezuka M: Characterization of the molecular clock in mouse peritoneal macrophages. Biol Pharm Bull 30: 621-626, 2007.

77. Huo M, Huang Y, Qu D, Zhang H, Wong WT, Chawla A, Huang Y and Tian XY: Myeloid Bmall deletion increases monocyte recruitment and worsens atherosclerosis. FASEB J 31: 1097-1106, 2017

78. Lam MT, Cho H, Lesch HP, Gosselin D, Heinz S, Tanaka-Oishi Y, Benner C, Kaikkonen MU, Kim AS, Kosaka M, et al: Rev-Erbs repress macrophage gene expression by inhibiting enhancer-directed transcription. Nature 498 $511-515,2013$
79. Sato S, Sakurai T, Ogasawara J, Takahashi M, Izawa T, Imaizumi K, Taniguchi N, Ohno $\mathrm{H}$ and Kizaki T: A circadian clock gene, Rev-erb $\alpha$, modulates the inflammatory function of macrophages through the negative regulation of $\mathrm{Ccl} 2$ expression. J Immunol 192: 407-417, 2014.

80. Xie M, Tang Q, Nie J, Zhang C, Zhou X, Yu S, Sun J, Cheng X, Dong N, Hu Y and Chen L: BMAL1-downregulation aggravates Porphyromonas gingivalis-induced atherosclerosis by encouraging oxidative stress. Circ Res 126: e15-e29, 2020.

81. Lucassen EA, Coomans CP, van Putten M, de Kreij SR, van Genugten JH, Sutorius RP, de Rooij KE, van der Velde M, Verhoeve SL, Smit JW, et al: Environmental 24-hr cycles are essential for health. Curr Biol 26: 1843-1853, 2016.

82. McAlpine CS, Kiss MG, Rattik S, He S, Vassalli A, Valet C, Anzai A, Chan CT, Mindur JE, Kahles F, et al: Sleep modulates haematopoiesis and protects against atherosclerosis. Nature 566: 383-387, 2019.

83. Schilperoort M, van den Berg R, Bosmans LA, van Os BW, Dollé M, Smits N, Guichelaar T, van Baarle D, Koemans L, Berbée J, et al: Disruption of circadian rhythm by alternating light-dark cycles aggravates atherosclerosis development in APOE*3-Leiden.CETP mice. J Pineal Res 68: e12614, 2020.

84. Arjona A and Sarkar DK: The circadian gene $m$ Per2 regulates the daily rhythm of IFN-gamma. J Interferon Cytokine Res 26: 645-649, 2006

85. Hashiramoto A, Yamane T, Tsumiyama K, Yoshida K, Komai K, Yamada H, Yamazaki F, Doi M, Okamura H and Shiozawa S: Mammalian clock gene Cryptochrome regulates arthritis via proinflammatory cytokine TNF-alpha. J Immunol 184: $1560-1565,2010$

86. Raffatellu M, George MD, Akiyama Y, Hornsby MJ, Nuccio SP, PaixaoTA,ButlerBP,ChuH,Santos RL,BergerT,etal:Lipocalin-2 resistance confers an advantage to Salmonella enterica serotype Typhimurium for growth and survival in the inflamed intestine. Cell Host Microbe 5: 476-486, 2009.

87. Yu X, Rollins D, Ruhn KA, Stubblefield JJ, Green CB, Kashiwada M, Rothman PB, Takahashi JS and Hooper LV: TH17 cell differentiation is regulated by the circadian clock. Science 342: 727-730, 2013.

This work is licensed under a Creative Commons Attribution-NonCommercial-NoDerivatives 4.0 International (CC BY-NC-ND 4.0) License. 